\title{
Acetabuloplastia extracapsular para tratamento de displasia coxofemoral em cão - relato de caso
}

\author{
Hip artroplasty for treatment of hip dysplasia in dog - case report \\ Márcio Poletto Ferreira ${ }^{1}$, Marcelo Meller Alievi ${ }^{1}$, Cristiano Gomes ${ }^{1}$, Carlos Afonso de Castro Beck ${ }^{1}$, \\ Juliana Voll2 ${ }^{2}$ Daniel $\mathrm{Sia}^{2}$, Antônio de Pádua Ferreira da Silva Filho ${ }^{1} \&$ César Dias Freire ${ }^{3}$
}

\begin{abstract}
RESUMO
A displasia coxofemoral é uma afecção que afeta principalmente cães de grande porte como São Bernardo e Pastor Alemão. Dentre as opções de tratamento cirúrgico, destaca-se a acetabuloplastia extracapsular. Esta técnica provém uma reconstrução da borda acetabular dorsal, auxiliando na estabilização e aumentando a congruência da articulação coxofemoral. O presente trabalho relata a utilização desta técnica para tratamento de displasia coxofemoral unilateral em um cão. No pósoperatório imediato o animal já utilizava adequadamente o membro operado e, 18 meses após o procedimento, foi verificado integração do enxerto à borda acetabular dorsal com uso funcional do membro.
\end{abstract}

Descritores: enxerto, borda acetabular dorsal, articulação coxofemoral.

\section{ABSTRACT}

The hip dysplasia is a disease that affects mainly giant breed dogs like Saint Bernard and German Shepherd. Between of the surgical techniques, stands out the darthroplasty. This technique comes a reconstruction of the dorsal acetabular rim, aiding in the stabilization and increasing the consistency of the hip joint. The present work tells the use of this technique for treatment of hip dysplasia in a dog. In the postoperative immediate the animal already used appropriately the operated member and, 18 months after the procedure, it was verified in the radiographic exam complete integration of the graft to the dorsal acetabular rim.

Key-words: graft, dorsal acetabular rim, hip joint. 


\section{INTRODUÇÃO}

A displesia coxofemoral é a doença ortopédica mais frequentemente encontrada em cães, sendo também verificada em humanos, felinos e eqüinos. É a principal causa de osteoartrite da articulação coxofemoral [5]. Ela ocorre normalmente de forma bilateral, mas não é incomum que uma das articulações esteja mais gravemente afetada que a outra e, em 3 a $30 \%$ dos casos, a displasia pode se apresentar unilateralmente [6].

Existem muitas técnicas cirúrgicas disponíveis para o tratamento da displasia coxofemoral dentre elas destaca-se a acetabuloplastia extracapsular como uma técnica indicada para animais que apresentam alterações na conformação da articulação coxofemoral, como achatamento acetabular, porém sem lesão à cartilagem articular [10].

A acetabuloplastia é um procedimento que têm como objetivos diminuir a instabilidade da articulação coxofemoral e prevenir a subluxação da cabeça femoral, através da colocação de aparato ósseo, cartilaginoso ou sintético, sobre a borda craniodorsal do acetábulo [1], aumentando assim, o grau de cobertura da cabeça femoral pelo acetábulo [2]. Este procedimento mantém a fisiologia articular com mínima morbidade, pois não ocorre nenhuma alteração na anatomia óssea da pelve, exceto por criar ou estender a borda dorsolateral do acetábulo. O presente trabalho tem por objetivo relatar o caso de um cão atendido no HCV-UFRGS, que foi submetido à acetabuloplastia extracapsular com enxerto autógeno para tratamento da displasia coxofemoral.

\section{RELATO DE CASO}

Um cão, macho, três anos, sem raça definida, foi trazido ao HCV-UFRGS com histórico de claudicação intensa do membro pélvico esquerdo sendo que os proprietários não relacionavam o início dos sinais com a ocorrência de trauma significativo. No exame clínico foi verificada presença de dor durante a abdução e adução deste membro, não sendo observadas outras alterações clínicas. O paciente foi encaminhado ao serviço de radiologia, onde foram realizados exames radiográficos nas projeções ventro-dorsal e láterolateral, sendo identificado displasia coxofemoral esquerda com subluxação articular, sem a presença de artrose (Figura 1A). Com este diagnóstico, decidiu-se pela acetabuloplastia extracapsular com enxerto autógeno da crista ilíaca.
Como medicação pré-anestésica foi utilizado acepromazina $(0,1 \mathrm{mg} / \mathrm{kg} / \mathrm{IM})$ associada com meperidina $(4 \mathrm{mg} / \mathrm{kg} / \mathrm{IM})$. A indução anestésica foi feita com propofol (4 mg/kg/IV) e, em seguida, o animal foi intubado e mantido em plano anestésico com inalação de isofluorano em oxigênio $100 \%$ com circuito anestésico semi-fechado. Como profilaxia antimicrobiana foi utilizado ampicilina (20 mg/kg/IV) $30 \mathrm{minu}-$ tos antes do início do procedimento cirúrgico.

A preparação do paciente incluiu tricotomia na região da articulação coxofemoral e sobre a crista ilíaca esquerda, e anti-sepsia com álcool-iodo-álcool. Iniciou-se a cirurgia com a coleta do enxerto ósseo, onde após incisão e divulsão dos tecidos moles, isolou-se uma porção da crista ilíaca e, com um motor de suspensão, foi coletado um fragmento ósseo com dois $\mathrm{cm}^{2}$ sendo este acondicionado em cuba estéril com solução fisiológica.

A articulação coxofemoral foi acessada conforme a técnica para abordagem da região craniodorsal [9], associada à osteotomia do trocânter maior do fêmur. Após localização da borda acetabular dorsal, iniciou-se a preparação do leito receptor através da curetagem do periósteo desta região. $\mathrm{O}$ enxerto previamente coletado foi fixado à borda acetabular dorsal por dois parafusos corticais (Figura 1B), sendo esta técnica também utilizada para estabilização do trocânter maior do fêmur, porém utilizando apenas um parafuso. A reaproximação da musculatura e subcutâneo, tanto da região da coleta como da implantação, foi feita utilizando fio mononáilon 2-0 com pontos de sultan e nas suturas de pele também foi utilizado fio mononáilon 2-0, mas com pontos isolados simples. No pós-operatório o animal recebeu como medicação analgésica tramadol $(2 \mathrm{mg} / \mathrm{kg} / \mathrm{IM})$ a cada 8 horas durante dois dias e meloxican $(0,2 \mathrm{mg} / \mathrm{kg} / \mathrm{VO})$ a cada 24 horas durante 7 dias.

O exame radiográfico pós-operatório revelou perfeita fixação do enxerto à borda acetabular dorsal (Figura 1C). Passados dois dias da cirurgia o animal já deambulava adequadamente e não apresentava dor no membro pélvico esquerdo sendo liberado para continuar o tratamento em casa. Foi solicitado ao proprietário que trouxesse o paciente a cada seis meses para controle radiográfico e, aos 18 meses de pósoperatório o exame radiográfico demonstrou completa integração do enxerto ao acetábulo (Figura 1D) e no exame físico foi observado apoio adequado do membro (Figura 1E). 


\section{DISCUSSÃO}

A displasia coxofemoral é uma das afecções mais comuns em cães de raças de grande porte como o Setter Inglês, o Pastor Alemão e o São Bernardo [11]. A técnica cirúrgica utilizada foi escolhida por se tratar de um caso de displasia coxofemoral onde havia arrasamento acetabular sem presença de artrose, como indicado por estudo recente [1]. Existem muitas opções de enxertos ou implantes para a reconstrução da borda acetabular dorsal, polímero osteocondutor biocompatível [3], cartilagem auricular bovina [1] e enxerto alógeno [8] já foram utilizados com sucesso. Neste caso optou-se pelo enxerto autógeno por se tratar de um material de fácil coleta, não necessitar de conservação, não haver risco de rejeição e com incorporação rápida ao acetábulo [7].

Durante a preparação do leito receptor para a fixação do enxerto ósseo, se realiza a denervação da cápsula articular através da curetagem do periósteo da região dorsal do acetábulo, isto elimina totalmente a dor existente antes da cirurgia e o animal deambula adequadamente nos primeiros dias de pós-operatório [4], como verificado no animal do nosso relato. Com 50 dias de pós-operatório já é possível identificar sinais de osteointegração do enxerto autógeno quando osso esponjoso é colocado na região [7]. Não foi identificado total integração do enxerto ao acetábulo com seis meses de pós-operatório, já após 18 meses da cirurgia foi visualizado no exame radiográfico total integração do enxerto à borda acetabular dorsal com remodelamento ósseo.

Baseando-se nos exames radiográficos e na deambulação adequada do paciente pode-se afirmar que a técnica de acetabuloplastia extracapsular com enxerto autógeno da crista ilíaca foi eficiente para tratamento de displasia coxofemoral unilateral neste caso.

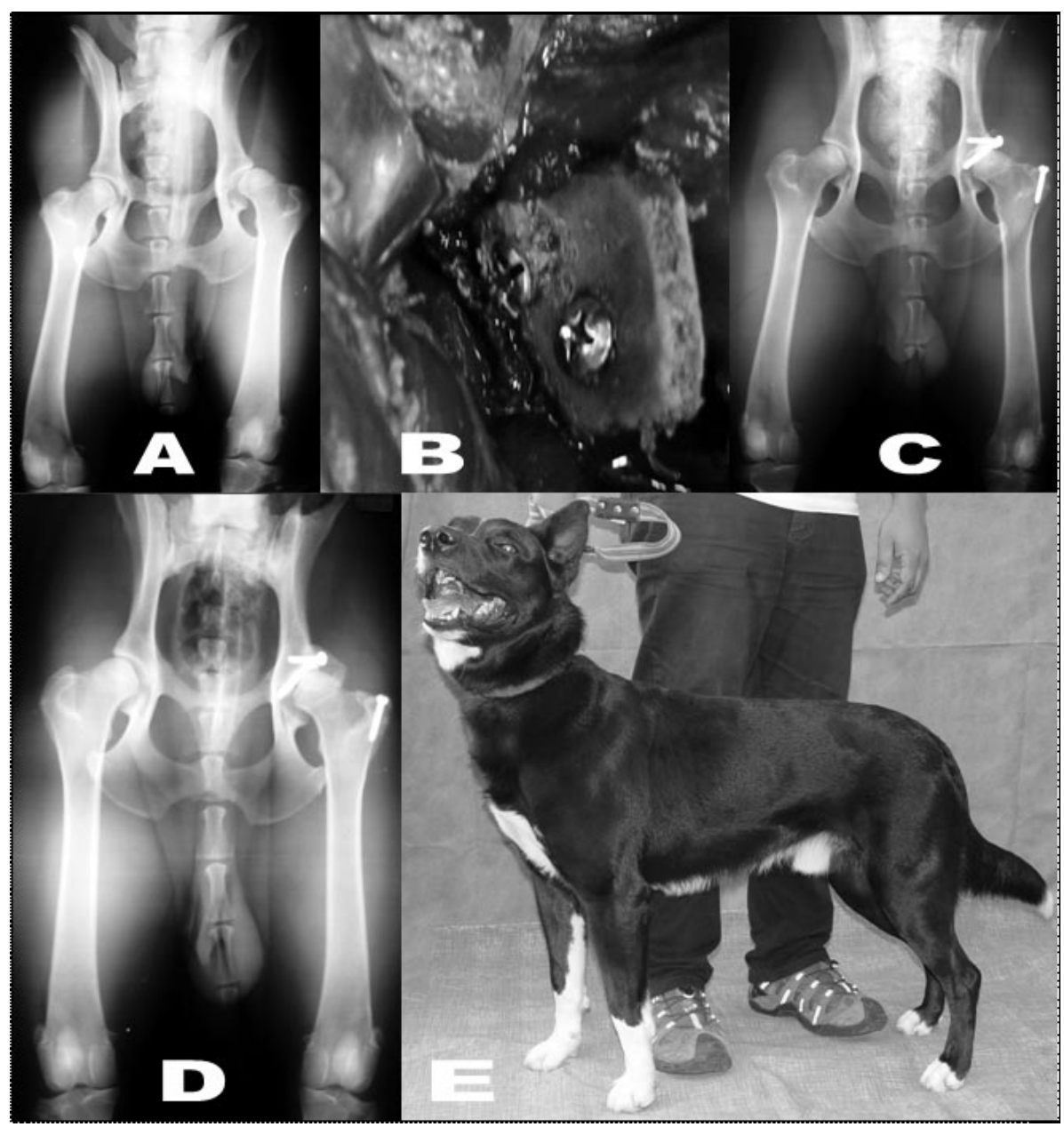

Figura 1. Exame radiográfico pré-cirúrgico da pelve na posição ventro-dorsal (A); Enxerto ósseo fixado à borda acetabular dorsal esquerda (B); Exame radiográfico da pelve na posição ventro-dorsal no pós-operatório imediato $(\mathrm{C})$; Exame radiográfico da pelve na posição ventro-dorsal após 18 meses da cirurgia (D); Animal em estação após 18 meses da cirurgia(E). 


\section{REFERÊNCIAS}

1 Costa J.L.O. 2003. Acetabuloplastia extracapsular em cães realizada com xenoenxerto de cartilagem auricular conservado em glicerina. 82f. Jaboticabal, SP. Tese (Doutorado em Ciências Veterinárias) - Faculdade de Ciências Agrárias e Veterinárias, Universidade Estadual Paulista, campus de Jaboticabal.

2 Coughlan A. 1996. Decision making in the management of canine hip dysplasia. In Practice. 18: 2-8.

3 Jensen D.J. \& Sertl G.O. 1992. Sertl shelf arthroplasty (BOP procedure) in the treatment of canine hip dysplasia. Veterinary Clinics of North America: Small Animal Practice. 22: 683-701.

4 Kinzel S., Hein S., von Scheven C. \& Küpper W. 2002. 10 years experience with denervation of the hip joint capsule for treatment of canine hip joint dysplasia and arthrosis. Berl Munch Tierarztl Wochenschr. 115: 53-56.

5 Lussier B., Lanthier T. \& Martineau-doizé B. 1994. Evaluation of biocompatible osteoconductive polymer shelf arthrosplasty for surgical correction of hip dysplasia in normal dogs. Canadian Journal Veterinary Research. 58: 173-180.

6 Mclaughlin R \& Tomlinson J. 1996. Radiographic diagnosis of canine hip dysplasia. Veterinary Medicine. 91: 36-47.

7 Moses P.A. 2000. Alteranative surgical methods for treating juvenile canine hip dysplasia. Australian Veterinary Journal. 78: 822-824.

8 Padilha Filho J.G. \& Selmi A.L. 2001. Evaluation of darthroplasty with bone allograft as a treatment for hip dysplasia in dogs. In: Proceeding of XXVI World Congress of The World Small Animal Veterinary Association (Vancouver, Canada). p.692.

9 Piermattei D.L. \& Johnson K.A. 2004. The pelvis and hip joint. In: An Atlas of Surgical Approaches to the Bones and Joints of the Dog and Cat. Philadelphia: Saunders, pp. 277-327.

10 Slocum B. \& Solcum T.D. 1998. Hip. In: Bojrab, M.J. (Ed). Current techniques in small animal surgery. 4.ed. Baltimore: Willians and Wikins, pp.1127-1178.

11 Tôrres R.C.S., Ferreira P.M. \& Silva D.C. 1999. Frequiência e assimetria da displasia coxofemoral em cães da raça Pastor Alemão. Arquivo Brasileiro de Medicina Veterinária e Zootecnia. 51: 153-156. 